\title{
Effect of Acupressure on Frequency and Severity of Nausea and Vomiting among Leukemic Children Undergoing Chemotherapy
}

\author{
HANAA G. MOHAMMED, M.Sc.*; AZZA A. ATTIA, D.N.Sc.**; HEWIDA A. HUSSEIN, D.N.Sc.** and \\ WAEL Z. KHALED, M.D.*** \\ The Department of Pediatric Nursing, Faculty of Nursing, Modern University for Technology \& Information* and \\ Cairo** Universities and The Department of Pediatric Oncology, National Cancer Institute, Cairo University***, Egypt
}

\begin{abstract}
Background: Acupressure is one of non-pharmacological techniques that can control chemotherapy induced nausea and vomiting among children with leukemia.
\end{abstract}

Aim of the Study: The current study aimed to evaluate the effect of acupressure on frequency and severity of nausea and vomiting among leukemic children undergoing chemotherapy.

Subjects and Methods: Quasi-experimental research design was utilized for the current study.

Setting: The current study was conducted at national Cancer Institute and sixth floor of Dar Essalam Hospital which affiliated to Cairo-University Hospitals.

Sample: A convenience sample was consisted of sixty school age children with leukemia divided into two equal half to acupressure and control group. The required data was collected by using four tools including personal data questionnaire sheet, nausea assessment sheet, vomiting assessment sheet and acupressure observational checklist.

Results: The current study revealed that frequency and severity of acute and delayed chemotherapy induced nausea and vomiting significantly decreased after application of acupressure technique. More than half of school age children having leukemia were less than nine years and male gender. There were statistically significant relationships between level of caregivers' education and with severity of acute and delayed nausea and vomiting. There were positive correlations between improvement of nausea and vomiting as well as improvement of delayed symptoms of nausea and vomiting.

Conclusion: The current study concluded that there was a positive effect of acupressure on decreasing frequency and severity of acute and delayed chemotherapy induced nausea and vomiting among school age children with leukemia.

Recommendations: The current study recommended that acupressure technique should be included in the chemotherapy protocol; children and their caregivers should teach the technique of acupressure before beginning of chemotherapy sessions.

Correspondence to: Dr. Hanaa G. Mohammed,

The Department of Pediatric Nursing, Faculty of Nursing, Modern University for Technology \& Information University, Egypt
Key Words: Acupressure - Chemotherapy - Leukemia Nausea-Vomiting school age-Children.

\section{Introduction}

LEUKEMIA is cancer that starts in blood-forming cells in the bone marrow. There is more than one type of leukemia. Each type of leukemia is named based on how fast it grows and the type of blood cell in which it begins [1]. Leukemia represents $30 \%$ of all childhood cancers [2] . Acute Lymphocytic Leukemia represents approximately $25 \%$ of cancer diagnoses among children younger than 15 years, with an annual incidence of up to 40 cases per million children in developed countries [3]. In Egypt, leukemia is the most common malignancy in children, accenting for almost one third of newly diagnosed pediatric cancer cases. The annual incidence is approximately four cases per 100.000 children per year in National Cancer Institute (NCI), Cairo-University, Egypt [4] .

Chemotherapy is used to treat most types of leukemia by using various anticancer drugs, either in combination or as single agents [2]. For treatment of acute lymphoblastic leukemia chemotherapy is a main core which destroy cancer cells through three phases; in form of remission induction, consolidation (or intensification) and maintenance (or continuation) therapies, as well as central nervous system prophylaxis and management of relapse [5]. Unfortunately alongside the therapeutic effects of chemotherapy there are side effects associated with chemotherapy such as nausea, vomiting [6].

Nausea and vomiting that induced by chemotherapy are two of the most frequent and troubling side effects most feared by pediatric patients during chemotherapy. Chemotherapy Induced Nausea and Vomiting (CINV) are still a common and debili- 
tating side effect and interfering with compliance with leukemia therapies and quality of life in spite of advances in antiemetic. The intrinsic emetogenicity of chemotherapy agents allowed grouping into four risk groups (high, moderate, low, and minimal risk of emetogenicity) [7].

Chemotherapy Induced Nausea and Vomiting (CINV) is broadly classified into acute, delayed and anticipatory type depending upon the time of onset: Acute CINV occurs in the first 24 hours after chemotherapy administration; delayed nausea and vomiting usually occurs 24 hours post treatment and can persist for as long as 5 days; and anticipatory nausea and vomiting usually occurs prior to the actual administration of chemotherapy based on previous experiences of nausea and vomiting of chemotherapy administration [8]. Despite recent advances in antiemetic therapy, CINV is still a challenging issue so using of non-pharmacological approaches are attractive given the possibility of ameliorating side effects without interacting with the many other medications [9].

Acupressure is one of the non-pharmacological methods for reducing the incidence of vomiting in which succeeded in preventing vomiting in $66 \%$ of the children [10]. Unfortunately using of acupressure therapy is less in Egypt in spite of effectiveness of this intervention and easily to learn how to perform acupressure for a variety of problems, including nausea [11]. Acupressure technique depends on using finger pressure to stimulate trigger points (acupoints) on the body for promoting blood circulation [9]. Oncology nurses play a pivotal role in the care of pediatric patients receiving chemotherapy, there are responsible for giving the pediatric patients and family specific information about the treatment's side effects and these interventions that can help minimize those effects. One of common and troublesome side effects experienced by cancer patients and have a negative impact on quality of life is CINV [12]. Oncology nurses possess the ability to educate pediatric patients undergoing potentially emetogenic therapy regarding possible risks and risk modifications, nonpharmacologic treatment and potential side effects from prescribed antiemetic [13].

So, the application of acupressure as a nonpharmacological technique used hopefully to decrease the CINV, assure the welfare among those children and to teach their caregivers the acupressure technique to be applied when needed. Also, to add to body of knowledge in pediatric nursing evidence based practice study in caring of school age children with leukemia.

\section{Aim of the study:}

The aim of the current study was to evaluate the effect of acupressure on frequency and severity of nausea and vomiting among leukemic children undergoing chemotherapy.

\section{Research hypotheses:}

- Leukemic school age children who apply acupressure in study group will experience less frequency and severity of nausea than those in control group.

- Leukemic school age children who apply acupressure in study group will experience less frequency and severity of vomiting than those in control group.

\section{Subjects and Methods}

\section{Setting:}

The study sample was collected from Pediatric Oncology Department of National Cancer Institute Cairo University and the sixth floor of Dar ElSsalam Hospital which affiliated to Cairo University Hospitals. In National Cancer Institute (NCI) the sample collected from Pediatric Department where situated in fifth floor, it includes three sections; inpatients (contains 70 beds), pediatric intensive care unit (contains 4 beds) and Intermediate Care Unit (contains 4 beds), these sections supported by a specialized clinical pharmacy unit, it provides care for children for free. The extended pediatric department for NCI is located at sixth floor of Dar El-Ssalam Hospital which data was collected from it also. The data collected all over 8 months, starting from June 2016 till January 2017.

\section{Research design:}

Quasi-experimental research design was utilized in the current study to collect required data.

\section{Subjects:}

A convenience sample was consisted of sixty school age children who fulfilling inclusion criteria was included in the current study and those children was divided into two equal half to acupressure and control group.

\section{Inclusion criteria of children:}

- School age children have acute lymphoblastic leukemia between 6-12 years old.

- Children receiving St. Jude protocol of treatment (total XV) and in the second phase of treatment (consolidation phase).

- Children who are receiving fixed dose of methotraxate. 


\section{Exclusion criteria for children:}

- Children who developed methotraxate toxicity.

- Children who experienced relapse.

- Children have no other diagnosis causing nausea and vomiting such as GIT malformation and/or disorder.

\section{Tools of data collection:}

There were four assessment tools were utilized to collect the required data for the current study as following:

1- A personal data questionnaire sheet developed by the research investigator, it included: Personal data of children and their caregivers such as child's age, gender and level of education for caregivers.

2- Nausea assessment sheet: It includes two parts:

- Part one: Baxter Animated Retching Faces (BARF) tool: Baxter Animated Retching Faces tool developed by Baxter, Watcha, Valentine, Leong, and Wyatt, (2011) [14] . This tool was adopted to assess severity of acute and delayed nausea, it included six items faces scale with 10 scores, each face used to determine severity of nausea score as the following face (0) considered "no nausea", face (1-3) considered mild nausea, face (4-6) considered moderate nausea and face (7-10) considered severe or "most nausea".

- Part two: Frequency of nausea assessed by how many times/day.

3- Vomiting assessment sheet: it includes two parts which were:

- Part one: Frequency of vomiting assessed by how many times/day.

- Part two: The severity of vomiting was adopted from American Academy of Pediatrics, (2014) [15] and included classification which based on frequency of vomiting episodes, with 1-2 episodes/day considered mild, 3-7 episodes/day considered moderate and 8 or more episodes/ day considered severe vomiting.

4- Acupressure observational checklist developed by the research investigator to evaluate application of acupressure technique by children/ caregivers. It contained 7 steps of performing acupressure such as; preparation phase, use proper finger, press on proper site, proper direction of pressure, strength of pressure, depth of pressure and duration of pressure, each correct step scored (1) and incorrect step scored (0).

\section{Tools validity:}

The content validity of the personal questionnaire and acupressure observational checklist tools reviewed by a panel of 3 experts in the fields of pediatric nursing, pediatric oncology and pediatric physiotherapy to test the content validity and no modifications were done.

The content validity for nausea assessment sheet (BARF) was assured by Baxter, et al., (2011) [14].

\section{Tools reliability:}

The reliability of the BARF is: The Spearman $\mathrm{p}$ correlation coefficient concurrent validity was 0.84-0.99.

\section{Pilot study:}

A pilot study was conducted on 6 school age children $(10 \%)$ from the total sample to evaluate the content of tools and its clarity, objectivity, feasibility and explained any discrepancies in the tools and to add or omit question and to estimate time required to fulfill sheets. The children included in the pilot study were included in the study sample.

\section{Legal and ethical considerations:}

Primary approval was obtained from the Research Ethical Committee in the Faculty of Nursing; Cairo University. An official permission obtained from Ethical Committee of National Cancer Institute (NCI) and from the head of Pediatric Hematology/Oncology Department. Written informed consent obtained from children' caregivers and oral acceptance obtained from children who participated in the current study after explaining the aim, nature of the study and assured confidentiality of data. The research investigator has a certificate of completion of training course on how to apply acupressure technique from the American Society of Traditional Science to maximize the benefits and decrease the harm for those children.

\section{Procedure:}

An official permission was obtained from the director of National Cancer Institute (NCI) and the head of Pediatric Department, during first cycle (which consisted of 4-5 days). The research investigator interviewed each child who fulfilled the inclusion criteria after simple explanation of the aim, benefits, nature and the duration of the study in the presence of caregivers, then the oral acceptance taken from the child and written informed consent obtained from the caregivers to get their acceptance as well as their cooperation. The research investigator obtained the personal data of 
the child and their caregivers; the interview was carried out at the child' room, then the research investigator taught each child and/or caregiver how to assess frequency and severity of nausea and vomiting by using CINV tools and demonstrated it to each child and/or caregiver till performed it correctly.

In the second day of first cycle when children started chemotherapy the research investigator assessed frequency and severity of acute CINV by herself, and then the child and/or caregiver assessed CINV for the rest of the day after the research investigator leave the hospital, then after 24 hours from starting chemotherapy the delayed CINV were assessed by the research investigator all over 3-5 days and by the child/caregivers at night.

Then at the discharge day after the first cycle of chemotherapy was completed, the research investigator hold for each child and/or caregiver teaching session about acupressure technique including knowledge about acupressure such as definition, benefits, preparation needed, and timing for application (which performed before mealtimes daily, before chemotherapy starting, before sleeping time and at any time if felt with sensation of nausea and vomiting), as well as instruction about duration of acupressure technique (which take about 3-5 minutes at each arm). Then each child and/or caregivers demonstrate how to apply acupressure technique until the procedure performed correctly then the research investigator evaluate the technique that performed by child and/or caregiver by using acupressure checklist.

At the second cycle of consolidation phase the research investigator applied the acupressure technique after simple revision with child and/or caregivers, also frequency and severity of acute and delayed CINV was assessed daily by using CINV tools, and at night the follow-up was done by child/or caregivers. The research investigator was assessed acute CINV at first day of chemotherapy administration and delayed CINV from day 2, till the day of discharge (day 4 or 5).

The researcher started firstly with the acupressure group then with control group. The same steps that carried out with the acupressure group carried out with the control group except nothing was given about acupressure either knowledge or application of technique. The research investigator assessed the effect of acupressure three times (post 1,2 and 3) to ensure the consistency of findings of acupressure technique.

\section{Data analysis:}

Data entry and statistical analysis were done using Statistical Package for Social Science (SPSS 20). Data were presented using descriptive statistics in the form of frequencies and percentages for qualitative variables, and means and standard deviations for quantitative variables. Quantitative continuous data were compared using Student $t$ test in case of comparisons between two independent groups. When normal distribution of the data could not be assumed, the non-parametric MannWhitney test was used instead of Student $t$-test. Qualitative categorical variables were compared using chi-square test. Spearman rank correlation was used for assessment of the inter-relationships among quantitative variables and ranked ones. In order to identify the independent predictors of the pre-post improvements in the scores of severity and frequency of nausea and vomiting, multiple linear regression analysis was used, and analysis of variance for the full regression models done. Statistical significance was considered at $p$-value $<0.05$.

\section{Results}

Table (1) shows that school age children were less than 9 years in control and acupressure group were $63.3 \%$ and $53.3 \%$ respectively. Male gender constitutes $73.3 \%$ and $63.3 \%$ respectively in control and acupressure group. Regarding caregivers' education the table also revealed that $60 \%$ and $46.7 \%$ respectively in control and acupressure group were educated which had primary to secondary education, while $6.7 \%$ and $30.0 \%$ respectively had university education in control and acupressure group. There were no statistical significant differences regarding the socio-demographic characteristics between control and acupressure group.

Table (2) displays that there is no statistically significant difference between control and acupressure group regarding the frequency of acute nausea pre-intervention, while there was an improvement in the frequency of acute nausea among acupressure group after intervention with statistically significant differences at $p=<0.001$.

Table (3) represents that in spite of the acupressure group have increased mean score of frequency of delayed nausea from the beginning before intervention, but the mean score improved significantly post intervention at $p=<0.001$.

Table (4) reveled that highly statistically significant improvement were detected regarding severity of acute nausea between acupressure and 
control group post interventions (post 1, 2 and 3), at $p=<0.001$.

Table (5) displayed that the mean scores of severity of delayed nausea among acupressure group was higher than the control group pre intervention, but post intervention improved significantly at $p=>0.001$.

Table (6) illustrated that there were no statistically significant differences between acupressure and control group pre-intervention regarding to mean score of severity of acute vomiting, while post intervention improvement in mean scores were detected among acupressure group with a highly statistically significant differences between both groups at $p=<0.001$.

Table (7) showed that the mean score of severity of delayed vomiting among acupressure group is increased than the control group before intervention, while post intervention there was improvement in mean scores of acupressure group than the control group with a highly statistically significant differences between both groups at $p=<0.001$.

Table (8) illustrated that among acupressure group there were positive correlation between severity of acute nausea and both of severity of delayed nausea and severity of acute vomiting at $r=0.376 \& r=0.383$ respectively, also positive correlation between severity of delayed nausea and both frequency of nausea and severity of delayed vomiting at $r=0.457$ and $r=0.520$ respectively, as well as positive correlation between severity of delayed vomiting and frequency of nausea at $r=$ 0.622 were detected.

Table (1): Frequency and percentage distribution of personal data of children and their caregivers among the study sample $(\mathrm{n}=60)$.

\begin{tabular}{|c|c|c|c|c|c|c|}
\hline & \multicolumn{2}{|c|}{$\begin{array}{l}\text { Control } \\
\text { group } \\
(n=30)\end{array}$} & \multicolumn{2}{|c|}{$\begin{array}{c}\text { Acupressure } \\
\text { group } \\
(\mathrm{n}=30)\end{array}$} & \multirow[t]{2}{*}{$\begin{array}{c}\chi^{2} \\
\text { test }\end{array}$} & \multirow[t]{2}{*}{$\begin{array}{c}p- \\
\text { value }\end{array}$} \\
\hline & No. & $\%$ & No. & $\%$ & & \\
\hline \multicolumn{7}{|l|}{ Child's age (year): } \\
\hline$<9$ & 19 & 63.3 & 16 & 53.3 & & \\
\hline $9+$ & 11 & 36.7 & 14 & 46.7 & 0.62 & 0.43 \\
\hline Mean \pm SD & \multicolumn{2}{|c|}{$8.1 \pm 2.6$} & \multicolumn{2}{|c|}{$8.7 \pm 2.5$} & & \\
\hline \multicolumn{7}{|l|}{ Gender: } \\
\hline Male & 22 & 73.3 & 19 & 63.3 & & \\
\hline Female & 8 & 26.7 & 11 & 36.7 & 0.69 & 0.41 \\
\hline \multicolumn{7}{|l|}{ Caregiver education: } \\
\hline Illiterate/read and write & 10 & 33.3 & 7 & 23.3 & & \\
\hline Primary to secondary & 18 & 60.0 & 14 & 46.7 & 5.48 & 0.06 \\
\hline University & 2 & 6.7 & 9 & 30.0 & & \\
\hline
\end{tabular}

*: Statistically significant at $p<0.05$.
Table (2): Comparison of mean scores between control and acupressure group regarding frequency of acute nausea pre-intervention and post interventions $(n=60)$.

\begin{tabular}{lcccc}
\hline $\begin{array}{l}\text { Frequency of } \\
\text { acute nausea }\end{array}$ & $\begin{array}{c}\text { Control } \\
\text { group } \\
(\mathrm{n}=30) \\
\text { Mean } \pm \mathrm{SD}\end{array}$ & $\begin{array}{c}\text { Acupressure } \\
\text { group } \\
(\mathrm{n}=30) \\
\text { Mean } \pm \mathrm{SD}\end{array}$ & $\begin{array}{c}\text { Mann } \\
\text { Whitney } \\
\text { test }\end{array}$ & $\begin{array}{c}p \text { - } \\
\text { value }\end{array}$ \\
\hline - Dose 1 (pre & $8.9 \pm 3.4$ & $9.7 \pm 3.3$ & 1.62 & 0.20 \\
intervention) & & & & \\
- Dose 2 (post) & $10.1 \pm 2.8$ & $0.4 \pm 0.9$ & 47.56 & $<0.001^{*}$ \\
- Dose 3 (post) & $10.3 \pm 2.4$ & $0.1 \pm 0.7$ & 50.69 & $<0.001^{*}$ \\
- Dose 4 (post) & $10.2 \pm 2.8$ & $0.1 \pm 0.3$ & 49.65 & $<0.001^{*}$ \\
\hline
\end{tabular}

*: Statistically significant at $p<0.05$.

Table (3): Comparison of mean scores between control and acupressure group regarding frequency of delayed nausea pre-intervention and post interventions $(\mathrm{n}=60)$.

\begin{tabular}{lcccc}
\hline $\begin{array}{l}\text { Frequency of } \\
\text { delayed nausea }\end{array}$ & $\begin{array}{c}\text { Control } \\
\text { group } \\
(\mathrm{n}=30) \\
\text { Mean } \pm \mathrm{SD}\end{array}$ & $\begin{array}{c}\text { Acupressure } \\
\text { group } \\
(\mathrm{n}=30) \\
\text { Mean } \pm \mathrm{SD}\end{array}$ & $\begin{array}{c}\text { Mann } \\
\text { Whitney } \\
\text { test }\end{array}$ & $\begin{array}{c}p \text { - } \\
\text { value }\end{array}$ \\
\hline Dose 1 (pre) & $3.9 \pm 1.7$ & $5.6 \pm 2.1$ & 9.87 & $0.002^{*}$ \\
Dose 2 (post) & $3.7 \pm 1.6$ & $0.1 \pm 0.2$ & 48.23 & $<0.001^{*}$ \\
Dose 3 (post) & $3.9 \pm 1.5$ & $0.0 \pm 0.1$ & 49.31 & $<0.001^{*}$ \\
Dose 4 (post) & $3.5 \pm 1.7$ & $0.0 \pm 0.0$ & 48.01 & $<0.001^{*}$ \\
\hline
\end{tabular}

*: Statistically significant at $p<0.05$.

Table (4): Comparison of mean scores between control and acupressure group regarding severity of acute nausea pre-intervention and post interventions $(\mathrm{n}=60)$.

\begin{tabular}{lcccc}
\hline $\begin{array}{l}\text { Severity of } \\
\text { acute nausea }\end{array}$ & $\begin{array}{c}\text { Control } \\
\text { group } \\
(\mathrm{n}=30) \\
\text { Mean } \pm \mathrm{SD}\end{array}$ & $\begin{array}{c}\text { Acupressure } \\
\text { group } \\
(\mathrm{n}=30) \\
\text { Mean } \pm \mathrm{SD}\end{array}$ & $\begin{array}{c}\text { Mann } \\
\text { Whitney } \\
\text { test }\end{array}$ & $\begin{array}{c}p \text { - } \\
\text { value }\end{array}$ \\
\hline Dose 1 (pre) & $1.6 \pm 1.0$ & $2.0 \pm 1.0$ & 3.21 & 0.07 \\
Dose 2 (post) & $1.8 \pm 0.9$ & $0.0 \pm 0.1$ & 46.62 & $<0.001^{*}$ \\
Dose 3 (post) & $1.8 \pm 0.8$ & $0.0 \pm 0.1$ & 47.76 & $<0.001^{*}$ \\
Dose 4 (post) & $2.0 \pm 0.9$ & $0.0 \pm 0.0$ & 48.57 & $<0.001^{*}$ \\
\hline
\end{tabular}

*: Statistically significant at $p<0.05$.

Table (5): Comparison of mean scores between control and acupressure group regarding severity of delayed nausea pre-intervention and post interventions $(n=60)$.

\begin{tabular}{lcccc}
\hline $\begin{array}{l}\text { Severity of } \\
\text { delayed nausea }\end{array}$ & $\begin{array}{c}\text { Control } \\
\text { group } \\
(\mathrm{n}=30) \\
\text { Mean } \pm \mathrm{SD}\end{array}$ & $\begin{array}{c}\text { Acupressure } \\
\text { group } \\
(\mathrm{n}=30) \\
\text { Mean } \pm \mathrm{SD}\end{array}$ & $\begin{array}{c}\text { Mann } \\
\text { Whitney } \\
\text { test }\end{array}$ & $\begin{array}{c}p- \\
\text { value }\end{array}$ \\
\hline Dose 1 (pre) & $2.3 \pm 0.6$ & $2.7 \pm 0.4$ & 5.78 & $<0.02^{*}$ \\
Dose 2 (post) & $2.2 \pm 0.7$ & $0.1 \pm 0.2$ & 47.15 & $<0.001^{*}$ \\
Dose 3 (post) & $2.2 \pm 0.6$ & $0.0 \pm 0.1$ & 49.43 & $<0.001^{*}$ \\
Dose 4 (post) & $2.3 \pm 0.6$ & $0.0 \pm 0.0$ & 50.81 & $<0.001^{*}$ \\
\hline
\end{tabular}

*: Statistically significant at $p<0.05$. 
Table (6): Comparison of mean scores between control and acupressure group regarding severity of acute vomiting pre-intervention and post interventions $(\mathrm{n}=60)$.

\begin{tabular}{lcccl}
\hline $\begin{array}{l}\text { Severity of } \\
\text { acute vomiting }\end{array}$ & $\begin{array}{c}\text { Control } \\
\text { group } \\
(\mathrm{n}=30) \\
\text { Mean } \pm \mathrm{SD}\end{array}$ & $\begin{array}{c}\text { Acupressure } \\
\text { group } \\
(\mathrm{n}=30) \\
\text { Mean } \pm \mathrm{SD}\end{array}$ & $\begin{array}{c}\text { Mann } \\
\text { test }\end{array}$ & $\begin{array}{c}p \text { - } \\
\text { value }\end{array}$ \\
\hline Dose 1 (pre) & $0.3 \pm 0.3$ & $0.4 \pm 0.3$ & 2.23 & 0.14 \\
Dose 2 (post) & $0.3 \pm 0.2$ & $0.0 \pm 0.0$ & 34.35 & $<0.001^{*}$ \\
Dose 3 (post) & $0.3 \pm 0.2$ & $0.0 \pm 0.0$ & 39.46 & $<0.001^{*}$ \\
Dose 4 (post) & $0.3 \pm 0.2$ & $0.0 \pm 0.0$ & 39.60 & $<0.001^{*}$ \\
\hline
\end{tabular}

*: Statistically significant at $p<0.05$.

Table (7): Comparison of mean scores between control and acupressure group regarding severity of delayed vomiting (days 2-5) pre-intervention and post interventions $(\mathrm{n}=60)$.

\begin{tabular}{lcccc}
\hline $\begin{array}{l}\text { Severity of } \\
\text { delayed } \\
\text { vomiting }\end{array}$ & $\begin{array}{c}\text { Control } \\
\text { group } \\
(\mathrm{n}=30) \\
\text { Mean } \pm \mathrm{SD}\end{array}$ & $\begin{array}{c}\text { Acupressure } \\
\text { group } \\
(\mathrm{n}=30) \\
\text { Mean } \pm \mathrm{SD}\end{array}$ & $\begin{array}{c}\text { Mann } \\
\text { Whitney } \\
\text { test }\end{array}$ & $\begin{array}{c}p \text { - } \\
\text { value }\end{array}$ \\
\hline Dose 1 (pre) & $1.7 \pm 1.4$ & $2.6 \pm 1.8$ & 6.85 & $0.009^{*}$ \\
Dose 2 (post) & $1.8 \pm 1.3$ & $0.1 \pm 0.5$ & 41.66 & $<0.001^{*}$ \\
Dose 3 (post) & $1.8 \pm 1.2$ & $0.1 \pm 0.2$ & 46.20 & $<0.001^{*}$ \\
Dose 4 (post) & $2.0 \pm 1.4$ & $0.0 \pm 0.0$ & 50.74 & $<0.001^{*}$ \\
\hline
\end{tabular}

*: Statistically significant at $p<0.05$.

Table (8): Correlation between nausea and vomiting improvement among children in acupressure group $(n=30)$.

\begin{tabular}{llllll}
\hline & \multicolumn{3}{c}{ Acupressure group $(\mathrm{n}=30)$} \\
\cline { 2 - 3 } Items & \multicolumn{2}{c}{ Nausea } & & Vomiting \\
\cline { 2 - 3 } \cline { 5 - 6 } & $\begin{array}{c}\text { Acute } \\
\text { severity }\end{array}$ & $\begin{array}{c}\text { Delayed } \\
\text { severity }\end{array}$ & $\begin{array}{c}\text { Acute } \\
\text { severity }\end{array}$ & $\begin{array}{c}\text { Delayed } \\
\text { severity }\end{array}$ \\
\hline Frequency of nausea & 0.23 & $0.457^{*}$ & 0.11 & $0.622^{* *}$ \\
Severity of delayed nausea & $.376^{*}$ & & & \\
Severity of acute vomiting & $.383^{*}$ & 0.07 & & \\
Severity of delayed vomiting & 0.07 & $0.520^{* *}$ & 0.25 & \\
\hline *: Statistically significant at $p<0.05$. & & & \\
$* *$ *: Statistically significant at $p<0.01$. & & &
\end{tabular}

\section{Discussion}

The current study results revealed that the mean scores of frequency, severity of acute and delayed nausea after intervention among acupressure group were decreased than the control group, these results go in accordance with Miao, et al., [16], Kaur, et al., [17], Esmail, et al., [18] who reported that frequency and severity of acute and delayed nausea was less experienced in children among acupressure group than children in the control group, the current study results not in accordance with Genc, et al., [19] and Noga, et al., [20] who reported that the acupressure band was not an effective approach in preventing chemotherapy induced nausea. From the researcher point of view, applying acupressure technique by fingers is more effective than acu- pressure band because the accuracy in depth of pressure and position of fingers, also feeling passing of energy under the fingers during application is indicator of successful technique and children have feeling with security especially if the technique done by children' caregivers.

The current study results showed that the mean scores of frequency and severity of acute and delayed vomiting attacks post intervention were decreased among acupressure group with highly statistically significant differences between acupressure and control group, these results go in the same line with Kaur, et al., [17], Esmail, et al., [18] and Babu, [21], who reported that there was statistically significant differences between acupressure and control group regarding severity and frequency of vomiting among acupressure group children. Unfortunately these results contradicted with Abusaad, [22] who studied the effect of acupressure on different diagnosis of pediatric cancer, and reported that the frequency of vomiting did not improved by acupressure, and the causes may be due to fear and stressors associated with using new technique beside the effect of chemotherapeutic drugs given with progressive stage of cancer diagnosis.

The results of the current study illustrated that the nausea and vomiting improved by time, these results are in accordance with Shin, [10] and Roscoe, et al., [23] who clarified that expectations of children toward acupressure technique play an important role in the effectiveness of the technique. From the researcher point of view, when the children feel better after application of the acupressure; the compliance of children and their caregivers were increased. Also, during the application of acupressure the research investigator observed that the child become calm and falling asleep during session.

The results of the current study revealed that with application of acupressure technique nausea improved than vomiting; these results go in the same line with Molassiotis et al., [24], who reported that improvements were higher in relation to nausea than vomiting. The research investigator observed also the delayed symptoms of nausea and vomiting improved better than acute, these results contradicted with Molassiotis, et al., [25], who illustrated that acupressure was better for controlling of acute nausea rather than delayed nausea and vomiting.

Regarding correlation between feeling of nausea and attacks of vomiting, the current study results raveled that there were a positive correlation be- 
tween nausea and vomiting and between acute and delayed chemotherapy induced nausea and vomiting, these results go in the same line with Lo and Hayman, [26], who reported that there were very strongly positive significant associations of total scores of nausea and vomiting.

The study results accept the research hypotheses that, school age children with leukemia who apply acupressure in study group experienced less frequency and severity of nausea than those in the control group and school age children with leukemia who apply acupressure in study group experienced less frequency and severity of vomiting than those in control group.

Regarding to personal characteristics of children with leukemia; the current study results revealed that more than half of children in acupressure and control group were less than 9 years old. These results go in the same line with Esmail, et al., [18] who mentioned that leukemia was among the most commonly diagnosed pediatric malignancies in children under 14 years. Unfortunately these results are not matched with the results of study had done by Hussein and Abd Elsadek, [27] who reported that more than half of children' age were above 9 years. This may reflect dangerous indicator for the occurrence of leukemia; which occur in younger than 9 children.

In relation to gender among school age children with leukemia, the current study results indicated that near two thirds in acupressure and control group were males, these results were in the same line with Esmail, et al., [18] Abusaad, [22] and Baraz, et al., [28], who reported that the pediatric leukemia among school age children were common affect males children than females. From the researcher point of view, males considered high risk group for many diseases such as blood disorder.

The current study results revealed that near one third of children caregivers in the acupressure group not educated and less than half had secondary or less educational level, these results was in accordance with El-Sawy, et al., [29], Hasan, et al., [30] Esparza, et al., [31] who reported that the majority of caregivers' education with acute lymphoblastic leukemia has secondary or less educational level. This might be related to the large number of caregivers are females and from rural areas where the education for girls needs more attention.

The current study results illustrated that there were a statistically significant negative relationship between level of caregivers' education with frequency and severity of acute nausea improvement.
These results may be due to higher educated parents may have correct technique of acupressure which improved nausea and vomiting among their children.

\section{Conclusion:}

In the light of the current study findings; it could be concluded that there was a positive effect of acupressure on decreasing frequency and severity of acute and delayed CINV among school age children with acute lymphoblastic leukemia.

\section{Recommendations:}

Based upon the findings of the current study, the following recommendations are suggested:

- Teaching the acupressure technique before beginning of chemotherapy for children with acute lymphoblastic leukemia and their caregivers.

- Use simple illustrative pamphlet about correct application of acupressure technique for children with acute lymphoblastic leukemia and their caregivers.

- Design unit for complementary therapy to deal with CINV by application of acupressure technique for children with acute lymphoblastic leukemia in Pediatric Oncology Hospitals.

\section{References}

1- National Comprehensive Cancer Network (NCCN): Acute lymphoblastic leukemia. Retrieved from http://www. nccn.org/professionals/physician gls/pdf/all.pdf, 2017.

2- American Cancer Society: Cancer facts \& figures, 1-9. Available at http://doi.org/10.1097/01.NNR.0000289503 22414.79, 2016.

3- HERNÁNDEZ A.F. and MENÉNDEZ P.: Linking Pesticide Exposure with Pediatric Leukemia: Potential Underlying Mechanisms. http://doi.org/10.3390/ijms1704046, 2016.

4- SHALBY R., ASHAAT N., A. EL WAHAB N., A. EL HAMEED M. and EL WAKEEL S.H.: Bcl-2 Expression $\&$ chromosomal abnormalities in childhood acute lymphoblastic leukemia. Academic Journal of Cancer Research, 3 (2): 34-43, 2010.

5- ZEKRI W., SEDKY M. and KHALIFA M.: The impact of homocysteine level on methotrexate induced neurotoxicity in children treated with St. Jude total XV acute lymphoblastic leukemia protocol. International Journal of Cancer Therapy and Oncology, 4 (1): 4111, 2016.

6- American Cancer Society: Cancer facts \& figures, Atlanta, Ga. Available at: www.cancer.org . Access at 6/6/2015, 2015.

7- COSTA A.L., ABREU C., PACHECO T.R., MACEDO D., SOUSA A.R., PULIDO C. and COSTA L.: Prevention of nausea and vomiting in patients undergoing oral anticancer therapies for solid tumors. Bio. Med. Research International, 1-7. http://doi.org/10.1155/2015/309601, 2015. 
8- LONGO D., NAVARI R. and AAPRO M.: Antiemetic prophylaxis for chemotherapy-induced nausea and vomiting. New England Journal of Medicine, 374 (14): 135667, 2016.

9- Memorial Sloan Kettering Cancer Center: Complementary therapies ease way during-treatment and recovery. Generated on February 23, 2016.

10- SHIN Y.H, KIM T., SHIN M. and JUON H.: Effect of acupressure on nausea and vomiting during chemotherapy cycle for Korean Postoperative Stomach Cancer Patients. Cancer Nurs., 27 (4): 267-74, 2011.

11- JACOBS S.: Integrative therapy use for management of side effects and toxicities experienced by pediatric oncology patients. Children (Basel, Switzerland), 1 (3): 42440, 2014.

12- JANELSINS M., TEJANI M., KAMEN C.H., PEOPLES A., MUSTIAN K. and MORROW G.: Current pharmacotherapy for chemotherapy-induced nausea and vomiting in cancer patients University of Rochester School of medicine and dentistry, 14 (6): 757-66, 2014.

13- ONCOLINK.: Management of chemotherapy-induced nausea and vomiting Pharmacotherapy, 10 (2): 129-45. Available at: http://doi.org/10.1179/acb.2010.067, 2017.

14- BAXTER A., WATCHA M., BAXTER W., LEONG T. and WYATT M.: Validation of a pictorial nausea rating scale for children, 83 (1): 1004-542, 2011.

15-American Academy of Pediatrics: The health of all children. Treating vomiting. Access at 3/10/2015. Available at: https://scholar.google.com.eg/scholar?hl=en\&as sdt $=0 \% 2 \mathrm{C} 5 \& \mathrm{q}=$ american+academy+of + pediatrics $+2014+$ vomiting+scale\&btnG $=, 2014$.

16- MIAO J., LIU X., WU C., KONG H., XIE W. and LIU K.: International Journal of Nursing Studies Effects of acupressure on chemotherapy-induced nausea and vomiting-a systematic review with meta-analyses and trial sequential analysis of randomized controlled trials. International Journal of Nursing Studies, 70, 27-37. http:// doi.org/10.1016/j.ijnurstu.2017.02.014. 2017.

17- KAUR R., MADAAN D. and KAUR R.: An experimental study to assess effectiveness of acupressure on relief of chemotherapy induced nausea and vomiting among cancer patients in selected hospital, Punjab. International. J. Pharm. Sci. Rev. Res., 34 (1): 243-6, 2015.

18- ESMAIL, DARWISH, EL SAYED, EL-SHANSHORY and EL SAADANY: Effect of progressive muscle relaxation technique versus acupressure on chemotherapy International Journal of Current Research, Vol. 6, Issue, 07, pp.7674-7682, July, 2014 Available online at http://. www.journalcra.com, 2015.

19- GENC A., CAN G. and AYDINER A.: The efficiency of the acupressure in prevention of the chemotherapy-induced nausea and vomiting. Support. Care Cancer, 21 (1): 25361, 2013.

20- NOGA S., TOLMAN A. and ROMAN J.: Acupressure as an adjunct to pharmacologic control of nausea, vomiting and retching $(\mathrm{N} / \mathrm{V})$ during blood and marrow transplantation (BMT): A randomized, placebo-controlled, algorithm based study. Proceedings of the American Society of Clinical Oncology 361 a, 2002.
21- BABU J.J.: Effectiveness of acupressure on nausea and vomiting among cancer patients receiving chemotherapy in a selected hospital. IOSR Journal of Nursing and Health Science (IOSR-JNHS), 1 (3): 9-13, 2014.

22- ABUSAAD S.: Effect of point 6 acupressure on chemotherapy associated nausea and vomiting among adolescents with cancer, 6(4), 122-129. http://doi.org/10.5430/ jnep.v6n4p122, 2016.

23- ROSCOE J., NEILL M. PIERRE P., HECKLER C, KAPTCHUK T., BUSHUNOW P., SHAYNE M., HUSTON A., QAZI R. and SMITH B.: An exploratory study on the effects of an expectancy manipulation on chemotherapyrelated nausea. Published in final edited form as: J. Pain Symptom Manage, September, 40 (3): 379-90. doi:10.1016/j.jpainsymman.2009.12.024, 2010.

24- MOLASSIOTIS A., RUSSELL W., HUGHES J., BRECKONS M., LLOYD-WILLIAMS M., RICHARDSON J., HULME C., BREARLEY S., CAMPBELL M., GARROW A. and RYDER W.D.: The effectiveness and costeffectiveness of acupressure for the control and management of chemotherapy-related acute and delayed nausea: Assessment of Nausea in Chemotherapy Research (ANCHoR), a randomised controlled trial. Health Technol. Assess., 17 (26): 1-114, 2014.

25- MOLASSIOTIS A., HELIN A.M., DABBOUR R. and HUMMERSTON S.: The effects of P6 acupressure in the prophylaxis of chemotherapy-related nausea and vomiting in breast cancer patients. Complement. Ther. Med., 15 (1): 3-12, 2007.

26- LO L.H. and HAYMAN L.L.: Parents associated with children in measuring acute and delayed nausea and vomiting. Nursing \& Health Sciences, 1 (3): 155-61. http://doi.org/10.1046/j.1442-2018.1999.00020.x. 1999.

27- HUSSEIN H. and SADEK B.: Acupressure for chemotherapy induced vomiting among school age children. World Journal of Medical Sciences, 8 (4): 373-81, 2013.

28- BARAZ S., MILADINIA M., MALEHI A.S., NOORI E.M. and BAEIS M.G.: Effect of the slow-stroke back massage on symptoms cluster (pain, fatigue and sleep disorders) in patients with acute leukemia. Avicenna Journal of Phytomedicine, 5 (24): 21. Retrieved from. http://www.embase.com/search/results?subaction= viewrecord\&from=export\&id=L72156677\%5 Cnhttp: //ajp. . mums.ac.ir/pdf $54548900156 \mathrm{ff} 21 \mathrm{a} 8 \mathrm{bf04ed2 \textrm {e } 0 0 \mathrm { ce } 4 \mathrm { c } 5}{ }^{\circ}$ 8eed.html, 2015.

29- EL-SAWY M.M., ISMAIL G.M., MAGDY H. and ELSAMMAN G.A.: Knowledge and home practices of caregivers having children with leukemia attending national cancer institute Cairo-University. Med. Journal. CairoUniversity, 81 (1): 601-8. Retrieved from www.medical journal of Cairo-University.net, 2013.

30- HASAN S.S., HUSSEIN K.A. and AL-ANI M.H.: Assessment of home care management for caregiver's having leukemic adolescent patient in Erbil city. Kufa Journal for Nursing Sciences, 2 (1), 2013.

31- ESPARZA M.C., IBARRA B.A., MARTÍNEZ J., HERNÁNDEZ D. and ZAMUDIO J.J.: Acute lymphoblastic leukemia in children: NANDA, NIC-NOC caregivers intervention. Journal of Nursing Education and Practice, 6 (7). http://doi.org/10.5430/jnep.v6n7p31, 2016. 


\section{تآثير العلاج بالضغط على ثقاط الطاقة على تكرار وشدة الغثيان والقئ

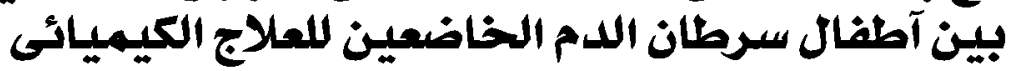

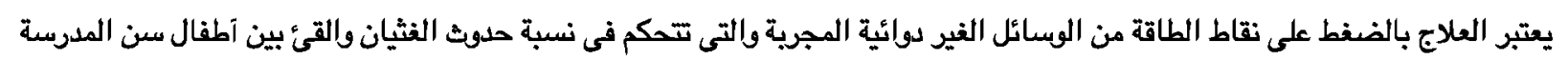
والذين يعانون من سرطان الدم الحاد ويتلقون العلاج الكيميائى.

كان هدف الدراسة الحالية هو تقويم تآثير العلاج بالضغط على نقاط الطاقة على تكراد ويشدة حلوث الغثيان والقئ بين آطفال سرطان الدم الخاضعين العلاج الكيميائى.

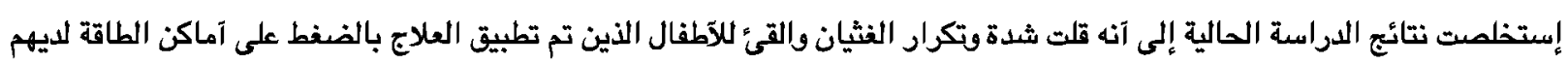

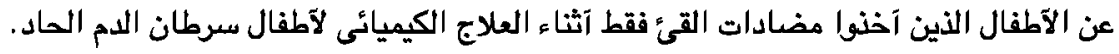

